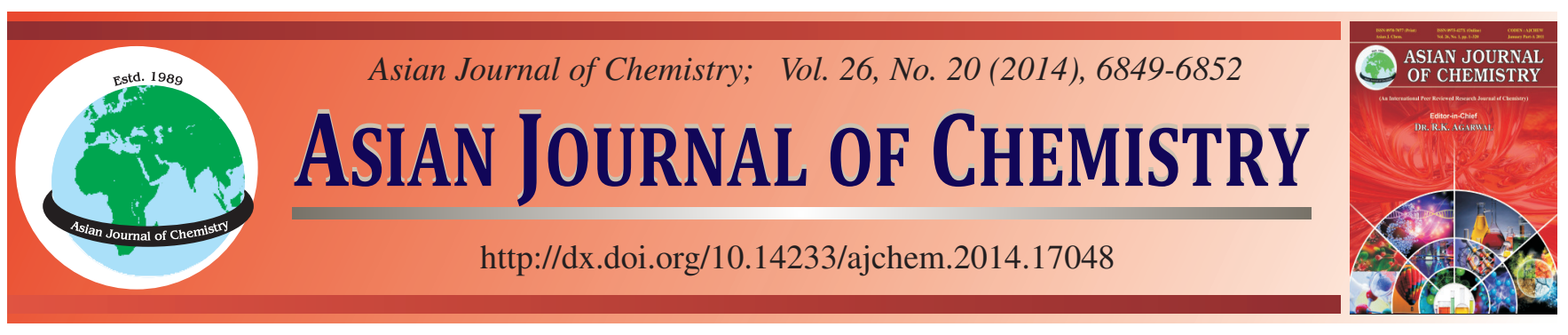

\title{
Simultaneous Determination of Environmental Endocrine Disruptors in Environmental Water by Gas Chromatography-Flame Ionization Detector
}

\author{
Bo Wang ${ }^{1}$, Xiaolin Wang ${ }^{2}$, Huaping Lin ${ }^{2}$, Chengyao $\mathrm{Li}^{3}, \mathrm{HaI}_{\mathrm{Zhu}}{ }^{4}, \mathrm{Siyuan} \mathrm{Bi}^{3,4, *}$ and Kaodi Lian ${ }^{2, *}$
}

${ }^{1}$ Handan College, Handan 056005, P.R. China

${ }^{2}$ The School of Public Health, Hebei Medical University, Shijiazhuang 050017, P.R. China

${ }^{3}$ Department of Transfusion Medicine, Southern Medical University, Guangzhou 510515, P.R. China

${ }^{4}$ Shenzhen Bioeasy Biotechnologies Co. Ltd., Shenzhen 518102, P.R. China

*Corresponding authors: E-mail: bisiyuan0129@126.com; liankaoqi@126.com

\begin{abstract}
A sensitive and selective method using gas chromatography-flame ionization detector (GC-FID) for analysis of 4-nonylphenol, bisphenol A, estradiol and estriol in aqueous environmental samples. The targets extracted by solid-phase extraction using Oasis HLB cartridges and derivatized with $\mathrm{N}, \mathrm{O}$-bis (trimethylsilyl) acetamide. The optimization of operating conditions influencing the performances of solidphase extraction and derivatization were studied. Calibration curves were linear in the range of 20 to $1000 \mathrm{ng} \mathrm{L}^{-1}$ for endocrine disruptors and the limit of detection (LOD) and limit of quantitation (LOQ) were in the range 3.6-6.4 $\mathrm{ng} \mathrm{L}^{-1}$ and 12.4-19.8 ng L $\mathrm{L}^{-1}$, respectively. The results of recovery indicated that the method had good precision and reproducibility. The established method was successfully applied to determination of the target exogenous compounds in man-made river waters in Shijiazhuang, China.
\end{abstract}

Keywords: Environmental endocrine disruptors, Gas chromatography, Derivatization, Solid-phase extraction.

\section{INTRODUCTION}

It is clear that a variety of chemicals and man-made pollutants present in the environment are capable of disturbing normal endocrine function in many species, possibly including human being ${ }^{1,2}$. So many chemicals as environmental endocrine disruptors have experimentally demonstrated to be able to affect endocrine processes to a great extent. Endocrine disruptors are a group of exogenous compounds, after entering into the human body. They can interfere with synthesis, secretion, transport, metabolism, binding, action and elimination of normal endocrine substances. These substances are extensive in sources, diverse in sorts and stable in property, so they are difficult to be degenerated ${ }^{3}$. Human exposure to endocrine disruptors results from dietary intake of these compounds as trace contaminants in food, drink, fruits and vegetables. Even at very low concentrations, endocrine disruptors can have endocrine-disrupting effects on organisms. The effects of endocrine disruptors on organism have many aspects including reproductive system ${ }^{4}$, embryonic development ${ }^{5}$, nervous system $^{6}$, immune system ${ }^{7}$, tumor genesis ${ }^{8}$, etc.

Among these compounds, 4-nonylphenol, bisphenol A, estradiol and estriol present significant research interest due to their extended use in several consumer and personal-care products and their toxicological and physico-chemical properties. 4-Nonylphenol is the degradation products of such non-ionic surfactants as alkylphenol polyethoxylates (APEOs) that exist mainly as intermediates in the manufacturing industry. It has been detected in river water, sewage sludge and fish tissue ${ }^{9}$. Bisphenol $\mathrm{A}$ is used in the manufacturing of polycarbonate plastics for packaging food and beverages, as well as for many other products that bring this contaminant in contact with humans ${ }^{10}$. Estradiol and estriol were sex hormone, accumulate in the environment and may give rise to health problems. It has been hypothesized that the statistically derived decrease in sperm counts over the last decades and the increasing incidence of testicular cancer and other disorders regarding male infertility may be caused by the intake of estrogens via food or drinking water ${ }^{11}$.

Due to their widespread use of the aforementioned compounds, an adequate analytical method for the simultaneous detection of these compounds in wastewater is needed. The most common technique used for the qualitative and quantitative analysis of endocrine disruptors is high performance liquid chromatography (HPLC) ${ }^{12,13}$. However, HPLC often does not provide sufficient separating performance and the UV-visible spectrum does not supply sufficient identifying power. To overcome these problems many researchers have 
employed high performance liquid chromatography-mass $(\text { HPLC-MS })^{14}$ or gas chromatography-mass (GC-MS) ${ }^{15}$ technique, although the methods have several advantageous features, the analytical instruments required are not generally present in common laboratories.

The purpose of this paper is to develop a sensitive and rapid method for simultaneous determinations of endocrine disruptors in water samples by gas chromatography-flame ionization detector (GC-FID). The method employs the solidphase extraction to separate the target compounds from the samples followed by simultaneous determinations of the silylated derivatives by GC-FID. N,O-bis(trimethylsilyl) acetamide was used as derivatization reagent to enhance sensitivity. The reactivity of endocrine disruptors towards the hydroxyl groups of four natural and synthetic estrogens (4nonylphenol, bisphenol A, estradiol and estriol) was compared and once the derivatization reagent was chosen, the influence of different parameters in the yield of the process was systematically investigated. The effects of sample $\mathrm{pH}$ in the recovery of the solid-phase extraction step and in the cleanliness of the obtained extracts were presented. Finally, the developed method was applied to the determination of endocrine disruptors in man-made river waters.

\section{EXPERIMENTAL}

4-Nonylphenol and bisphenol A were purchased from National Institutes for Food and Drug Control (Beijing, China). Estradiol and estriol were purchased from Sigma-Aldrich (St. Louis, MO, USA). The derivatization reagent N,O-bis(trimethylsilyl) acetamide was purchased from Beijing Bailingwei Chemical Technology Co., Ltd. (Beijing, China). N,O-bis(trimethylsilyl) trifluoroacetamide (BSTFA) and $N$-methyl- $N$ (trimethylsilyl) trifluoroacetamide (MSTFA) were from Sigma-Aldrich (St. Louis, MO, USA). LC grade methanol and ethyl acetate were purchased from Shanghai Experiment Reagent Co., Ltd. (Shanghai, China). Individual stock solutions of the estrogenic compounds were prepared in methanol. Solidphase extraction cartridge $(6 \mathrm{~mL} / 200 \mathrm{mg})$ of Oasis HLB was obtained from Waters (Milford, MA, USA). Milli-Q water was used throughout this work.

\section{Solid-phase extraction}

River samples were filtered after received using $0.45 \mu \mathrm{m}$ pore size cellulose filters. After filtration, the $\mathrm{pH}$ was adjusted to 2 with $0.1 \mathrm{M} \mathrm{HCl} .200 \mathrm{ng}$ of each 4-nonylphenol, bisphenol A, estradiol, estriol were spiked in $1000 \mathrm{~mL}$ of ultrapure water for the recovery test. A 24-port vacuum manifold supplied the vacuum of the solid-phase extraction column. The cartridge was conditioned with $5 \mathrm{~mL}$ of ethyl acetate to remove residual bonding agents, followed by $5 \mathrm{~mL}$ of methanol, in which methanol was drawn through the cartridges under low vacuum to ensure that the sorbents were soaked in methanol. After 5 min of soaking in methanol, $15 \mathrm{~mL}$ ultrapure water was passed through the cartridge at a rate of $1-2 \mathrm{~mL} \mathrm{~min}^{-1}$. Then, water samples were extracted at a flow rate less than $5 \mathrm{~mL} \mathrm{~min}^{-1}$. After washing the cartridge with $10 \mathrm{~mL}$ of water-methanol $(5: 1 \mathrm{v} / \mathrm{v})$, the cartridges were dried under vacuum for $0.5 \mathrm{~min}$ and then the analytes were eluted to $20 \mathrm{~mL}$ vials from the sorbent with $10 \mathrm{~mL}$ of ethyl acetate at a flow rate of $1 \mathrm{~mL}$ $\min ^{-1}$. The eluates were evaporated to dryness at $50{ }^{\circ} \mathrm{C}$, under a gentle stream of nitrogen gas.

Derivatization procedure: $\mathrm{N}, \mathrm{O}$-bis(trimethylsilyl) acetamide $(50 \mu \mathrm{L})$ was added to the dry extracts to derivatize the analytes. The mixtures were kept at about $70^{\circ} \mathrm{C}$ for $40 \mathrm{~min}$. After cooling to room temperature, $1 \mu \mathrm{L}$ of each of these solutions was injected into the GC for analysis.

GC-MS analysis: GC-MS analysis was performed on an Agilent (Little Falls, DE, USA) gas chromatograph 7890 equipped with an electronically controlled split/splitless injection port. The GC separation was conducted with an HP$5 \mathrm{MS} 30 \mathrm{~m} \times 0.25 \mathrm{~mm}$ I.D., $0.25 \mu \mathrm{m}$ film thickness column (Agilent, CA, USA). Nitrogen was used as the carrier gas at a constant flow rate of $1 \mathrm{~mL} \mathrm{~min}{ }^{-1}$. A splitless injection of $1 \mu \mathrm{L}$ was made at $260^{\circ} \mathrm{C}$. The GC oven was operated with the following temperature program: initial temperature $150{ }^{\circ} \mathrm{C}$ held for $2 \mathrm{~min}$, ramped at $10{ }^{\circ} \mathrm{C} \mathrm{m^{-1 }}$ to $270{ }^{\circ} \mathrm{C}$ and held for 11 min. Total run time was $25 \mathrm{~min}$.

\section{RESULTS AND DISCUSSION}

Solid-phase extraction procedure: For the optimum conditions of solid-phase extraction, a number of parameters were studied for spiked water samples. Since the extraction is a complex process and according to the character of the sample (polarity, solubility and $\mathrm{pK}_{\alpha}$ ), the $\mathrm{pH}$ of water, wash solution and eluent should be carefully chosen.

In ideal solid-phase extraction procedure, the analytes and few disruptors would be absorbed onto the packing solid phase under appropriate conditions and the analytes were expected to be eluted from the absorbed materials with smallest volume of selected solvents, so as to give a high concentration factor. To obtain better results, alteration of the $\mathrm{pH}$ of the water was carried out by monitoring the extraction efficiency of endocrine disruptors at $\mathrm{pH} 1-5$. The results are shown in Table-1, the recoveries of 4 endocrine disruptors reach maximum at $\mathrm{pH} 2$ 3 and, then, decreased by increasing $\mathrm{pH}$. The overall evaluation, $\mathrm{pH} 2$ was chosen in this study.

\begin{tabular}{lccccc}
\multicolumn{5}{c}{ TABLE-1 } \\
& \multicolumn{5}{c}{ RECOVERIES OF 4 ENDOCRINE } \\
& DISRUPTORS AT DIFFERENT pH \\
\hline \multirow{2}{*}{ Compound } & \multicolumn{5}{c}{$\mathrm{pH}$} \\
\cline { 2 - 6 } & 1 & 2 & 3 & 4 & 5 \\
\hline 4-Nonylphenol & 50.6 & 68.8 & 70.5 & 43.5 & 42.1 \\
Bisphenol A & 68.4 & 95.6 & 82.6 & 75.6 & 68.6 \\
Estradiol & 72.6 & 92.7 & 83.4 & 80.3 & 81.5 \\
Estriol & 76.6 & 88.5 & 89.6 & 77.5 & 75.4 \\
\hline
\end{tabular}

In the eluting procedure, the mixing solution of watermethanol was selected considering popularity of solvent. Volume of eluent was fixed as $10 \mathrm{~mL}$, eluting curves of four endocrine disruptors were studied through varying the proportion of water and methanol. Wash solution could be selected as $10 \mathrm{~mL}$ watermethanol $(5: 1, v / v)$, which could wash out most of the impurities and remove residual water in cartridge without breakthrough and eluent could be $10 \mathrm{~mL}$ ethyl acetate, which had stable recoveries and easy to dryness in the next step.

Derivatization procedure: For the optimum conditions of derivatization, a number of parameters were studied for 
spiked water samples containing $200 \mathrm{ng} \mathrm{L}^{-1}$ endocrine disruptors, including the amount of $\mathrm{N}, \mathrm{O}$-bis(trimethylsilyl) acetamide, reaction temperature and reaction time. The effects of the amount of $\mathrm{N}, \mathrm{O}$-bis(trimethylsilyl) acetamide on the derivatization yields were studied in the range of 50-200 $\mu \mathrm{L}$. Results showed that the degree of derivatization was not affected by the volume of the derivatization reagent. Thus, the smallest volume $(50 \mu \mathrm{L})$ of the $N, O$-bis (trimethylsilyl) acetamide was chosen for further experiments. The effects of reaction temperature on the derivatization yields were examined at 40, 50, $60,70,80$ and $90^{\circ} \mathrm{C}$. The derivatization yield increased with the increasing temperature in the region from 40 to $70^{\circ} \mathrm{C}$ and then decreased. Consequently, the reaction temperature was fixed at $70{ }^{\circ} \mathrm{C}$. In addition, the derivatization yields were evaluated by varying reaction time at $70{ }^{\circ} \mathrm{C}$. It was found that the peak areas of the derivatives were almost constant when the reaction time was above $40 \mathrm{~min}$. Therefore, the derivatization reaction carried out at about $70{ }^{\circ} \mathrm{C}$ for $40 \mathrm{~min}$.

For endocrine disruptors analysis by GC, different derivatization reagents have been used in order to improve sensitivity. These include $N, O$-bis (trimethylsilyl) trifluoroacetamide ${ }^{15}$, pentafluorobenzyl ${ }^{16}, N$-methyl- $N$-(tert-butyldimethylsilyl) trifluoroacetamide ${ }^{17}, \mathrm{~N}$-methyl- $\mathrm{N}$-(trimethylsilyl)trifluoroacetamide $^{18}$ and direct aqueous derivatization using acetic anhydride ${ }^{19}$. Among these methods, N,O-bis(trimethylsilyl) trifluoroacetamide and $\mathrm{N}$-methyl- $\mathrm{N}$-(tert-butyldimethylsilyl) trifluoroacetamide are the most popular derivatization approaches for endocrine disruptors. Few reports used $\mathrm{N}, \mathrm{O}$-bis(trimethylsilyl) acetamide as derivatization reagent. Therefore, the comparison of this method with other derivatization methods ${ }^{15,18}$ has been tested (Fig. 1). It can be seen, the derivati-

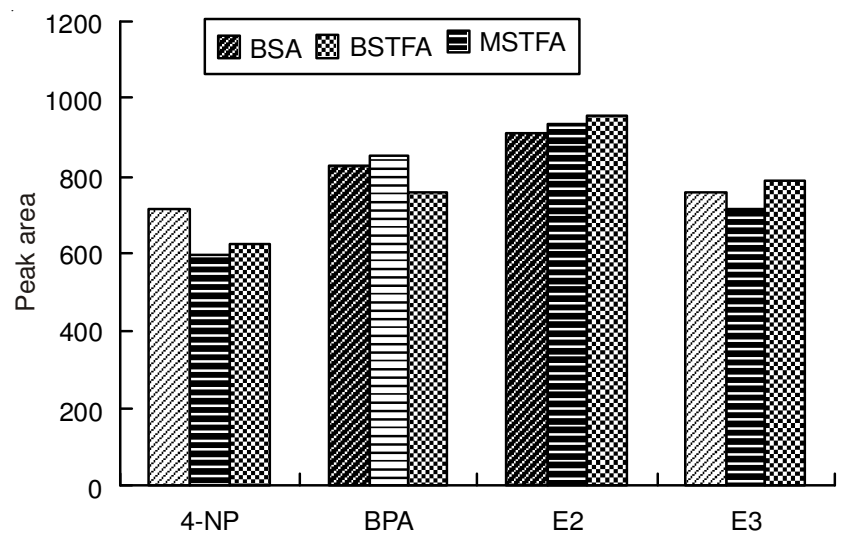

Fig. 1. Peak areas of 4 endocrine disruptors using different derivatization approaches zation efficiencies of bisphenol A, estradiol and estriol was nearly equal by the three derivatization methods, but the derivatization efficiency of 4-nonylphenol by this method was higher than by two other methods.

Method validation: To evaluate the linearity of the developed method, calibration curves that ranged from 20$1000 \mathrm{ng} \mathrm{L}^{-1}$ for the endocrine disruptors were constructed and calculated according to the method of least squares, relating y (the peak area ratio of the endocrine distruptors-derivatives) to $\mathrm{x}$ (the concentration of the endocrine disruptors in $\mathrm{ng} \mathrm{L}^{-1}$ ). The standard mixture solution was analyzed in triplicate. Table2 lists the data for the linear ranges, correlation coefficients, the limits of detection (LOD) and the limits of quantification (LOQ). The calibration curves of the analytes showed good linearity within the given concentration ranges, with correlation coefficients $\left(\mathrm{r}^{2}\right)$ greater than 0.990 . The LOD (based on signalto-noise ratio of $3, \mathrm{~S} / \mathrm{N}=3$ ) of the four compounds were in the range 3.6-6.4 $\mathrm{ng} \mathrm{L}^{-1}$ and $\mathrm{LOQ}(\mathrm{S} / \mathrm{N}=10)$ were in the range 12.4-19.8 $\mathrm{ng} \mathrm{L}^{-1}$.

\begin{tabular}{lcccc}
\multicolumn{5}{c}{ TABLE-2 } \\
\multicolumn{5}{c}{$\begin{array}{l}\text { LINEAR RANGE, LOD, AND LOQ } \\
\text { OF 4 ENDOCRINE DISRUPTORS }\end{array}$} \\
\hline \multicolumn{1}{c}{ Compound } & $\begin{array}{c}\text { Linear range } \\
\left(\mathrm{ng} \mathrm{L}^{-1}\right)\end{array}$ & $\begin{array}{c}\text { Correlation } \\
\text { coefficients }\left(\mathrm{r}^{2}\right)\end{array}$ & $\begin{array}{c}\text { LOD } \\
(\mathrm{ng} / \mathrm{L})\end{array}$ & $\begin{array}{c}\text { LOQ } \\
\left(\mathrm{ng} \mathrm{L}^{-1}\right)\end{array}$ \\
\hline 4-Nonylphenol & $20-1000$ & 0.995 & 5.8 & 16.8 \\
Bisphenol A & $20-1000$ & 0.998 & 4.4 & 14.2 \\
Estradiol & $20-1000$ & 0.990 & 3.6 & 12.4 \\
Estriol & $20-1000$ & 0.992 & 6.4 & 19.8 \\
\hline
\end{tabular}

Different spiked concentrations of endocrine disruptors in the ultrapure water $\left(50,200,500 \mu \mathrm{g} \mathrm{mL}^{-1}\right)$ were adopted to examine the recovery and precision of the method (Table-3). The intra-day precision (\%, RSD) in water for endocrine disruptors at the low concentration level was $\leq 4.2 \%$, at medium and high concentration levels were $\leq 2.9 \%$. The average recoveries of different concentrations ranged from 86.4 to $106.5 \%$. The inter-day recovery and precision were determined at the same three concentration levels over a period of 3 days $(n=6)$. The inter-day precision $(\%, \mathrm{RSD})$ at the low concentration level was $\leq 5.5 \%$, at medium and high concentration levels $\leq 3.6 \%$. The assay accuracy ranged from 85.3 to $105.3 \%$. The results showed the method had good precision even at the low concentrations.

Analysis of real samples: The method developed was applied to the determination of chosen endocrine disruptors at four different locations in man-made river waters in

\begin{tabular}{llccc|ccc}
\multicolumn{1}{c}{ RECOVERIES AND PRECISIONS OF 4 ENDOCRINE DISRUPTORS IN WATER } \\
\hline \multirow{2}{*}{ Compound } & \multirow{2}{*}{ Spiked level (ng/L) } & \multicolumn{3}{c}{ Intra-day (n=6) } & \multicolumn{4}{c}{ Inter-day (n = 6) } \\
\cline { 3 - 9 } & & 50.0 & 200 & 500 & 50.0 & 200 & 500 \\
\hline \multirow{2}{*}{ 4-Nonylphenol (4-NP) } & Recovery (\%) & 86.4 & 89.3 & 92.6 & 85.3 & 87.4 & 88.5 \\
& Precision (\%, RSD) & 3.4 & 2.8 & 1.7 & 3.8 & 2.7 & 3.6 \\
\hline \multirow{2}{*}{ Bisphenol A (BPA) } & Recovery (\%) & 98.6 & 99.4 & 106.5 & 95.3 & 96.4 & 94.6 \\
& Precision (\%, RSD) & 2.6 & 1.4 & 2.6 & 4.6 & 2.9 & 2.4 \\
\hline \multirow{2}{*}{ Estradiol (E2) } & Recovery (\%) & 95.6 & 98.4 & 99.1 & 92.5 & 93.5 & 98.2 \\
& Precision (\%, RSD) & 3.4 & 2.6 & 1.8 & 4.7 & 2.4 & 2.8 \\
\hline \multirow{2}{*}{ Estriol (E3) } & Recovery (\%) & 105.2 & 106.4 & 102.5 & 98.6 & 94.5 & 105.3 \\
& Recovery (\%) & 4.2 & 2.8 & 2.9 & 5.5 & 3.4 & 3.6 \\
\hline
\end{tabular}


Shijiazhuang, China. As shown in Table-4, the concentrations of 4-nonylphenol, estradiol and estriol were relatively low, many of which are frequently below their LOD. But the bisphenol A has been detected in all samples. Fig. 2 showed the typical chromatograms of a real sample and the aqueous standard of $200 \mathrm{ng} \mathrm{L}^{-1}$ endocrine disruptors.

\begin{tabular}{ccccc}
\multicolumn{5}{c}{ TABLE 4 } \\
CONCENTRATION OF ENDOCRINE DISRUPTORS IN \\
\multicolumn{4}{c}{ MAN-MADE RIVER WATERS IN SHIJIAZHUANG, CHINA } \\
\cline { 2 - 5 } Compound & \multicolumn{4}{c}{ Location } \\
\cline { 2 - 5 } & 1 & 2 & 3 \\
\hline 4-Nonylphenol & $38.4 \pm 1.04$ & $<$ LOD & $26.5 \pm 0.98$ & $<$ LOD \\
Bisphenol A & $79.4 \pm 2.12$ & $56.6 \pm 1.56$ & $42.6 \pm 1.23$ & $57.2 \pm 1.42$ \\
Estradiol & $25.3 \pm 0.65$ & $42.1 \pm 1.02$ & $<$ LOD & $<$ LOD \\
Estriol & $<$ LOD & $<$ LOD & $<$ LOD & $31.2 \pm 0.85$ \\
\hline
\end{tabular}
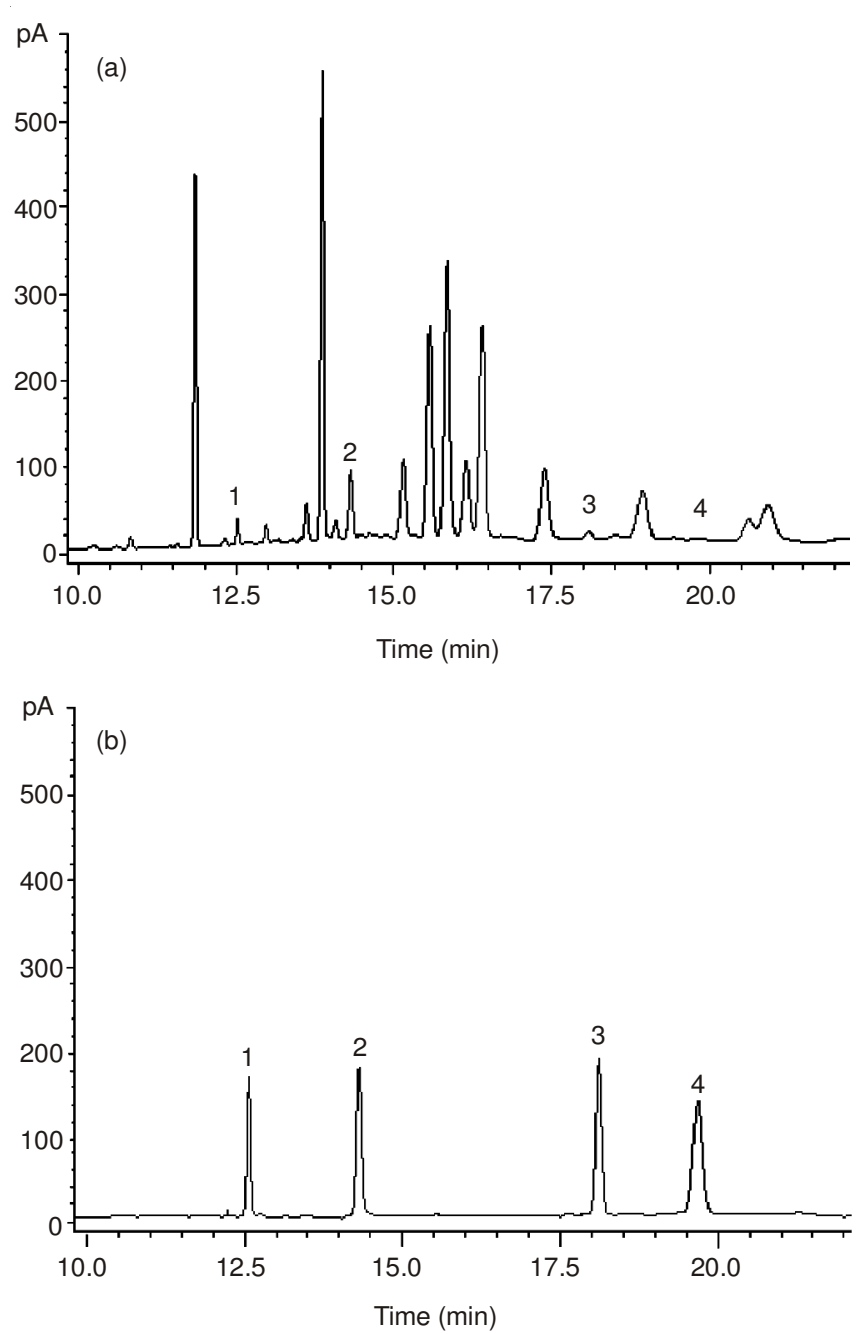

Fig. 2. Typical chromatograms of a real sample (a) and the aqueous standard of $200 \mathrm{ng} \mathrm{L}^{-1}$ endocrine disruptors (b) Compound: 1, 4-nonylphenol; 2, bisphenol A; 3, estradiol; 4, estriol

\section{Conclusion}

The method using SPE-GC-FID provided a simple and sensitive means for extraction and analysis of endocrine disruptors including 4-nonylphenol, bisphenol A, estradiol and estriol. The target endocrine disruptors were first derivatized by $N, O$-bis (trimethylsilyl) acetamide. In comparison with other sample preparation methods, the derivatization efficiency of 4-nonylphenol by this method was higher than others. The method has been validated for the analysis of the endocrine disruptors in water samples and the results obtained concerning linearity, recovery, precision were satisfactory, which indicated that the developed method could be well adopted for use in water quality surveillance programs.

\section{ACKNOWLEDGEMENTS}

The authors acknowledge the financial support from the National Natural Science Foundation of China (No. 81302471); the Natural Science Foundation of Hebei Province (No. H2014206345); International Science \& Technology Cooperation Project of China (No. 2011DFA32930), and Shenzhen Technology Research \& Development Foundation project (No. JSGG20130624152620659).

\section{REFERENCES}

1. B. Dunbar, M. Patel, J. Fahey and C. Wira, Mol. Cell. Endocrinol., 354, 85 (2012).

2. W. Mnif, A.I.H. Hassine, A. Bouaziz, A. Bartegi, O. Thomas and B. Roig, Int. J. Environ. Res. Public Health, 8, 2265 (2011).

3. S.N. Kolle, T. Ramirez, H.G. Kamp, R. Buesen, B. Flick, V. Strauss and B. van Ravenzwaay, Regul. Toxicol. Pharmacol., 63, 259 (2012).

4. M. Uzumcu and R. Zachow, Reprod. Toxicol., 23, 337 (2007).

5. M. Uzumcu, H. Suzuki and M.K. Skinner, Reprod. Toxicol., 18, 765 (2004).

6. A. Miodovnik, S.M. Engel, C. Zhu, X. Ye, L.V. Soorya, M.J. Silva, A.M. Calafat and M.S. Wolff, Neurotoxicology, 32, 261 (2011).

7. J. Calemine, J. Zalenka, E. Karpuzoglu-Sahin, D.L. Ward, A. Lengi and S.A. Ahmed, Toxicology, 194, 115 (2003).

8. P.P. López-Casas, S.C. Mizrak, L.A. López-Fernández, M. Paz, D.G. de Rooij and J. del Mazo, Reprod. Toxicol., 33, 106 (2012).

9. R. Céspedes, K. Skryjová, M. Raková, J. Zeravik, M. Fránek, S. Lacorte and D. Barceló, Talanta, 70, 745 (2006).

10. Q. Zhou, Y. Gao and G. Xie, Talanta, 85, 1598 (2011).

11. T. Cajthaml, Z. Kresinová, K. Svobodová, K. Sigler and T. Rezanka, Environ. Pollut., 157, 3325 (2009).

12. K. Mitani, S. Narimatsu, F. Izushi and H. Kataoka, J. Pharm. Biomed. Anal., 32, 469 (2003).

13. T. Li, J. Xu, J.H. Wu and Y.Q. Feng, J. Chromatogr. A, 1216, 2989 (2009).

14. W. Yan, Y. Li, L. Zhao and J.M. Lin, J. Chromatogr. A, 1216, 7539 (2009).

15. R. Liu, J.L. Zhou and A. Wilding, J. Chromatogr. A, 1022, 179 (2004).

16. D.D. Fine, G.P. Breidenbach, T.L. Price and S.R. Hutchins, J. Chromatogr. A, 1017, 167 (2003).

17. A. Shareef, C.J. Parnis, M.J. Angove, J.D. Wells and B.B. Johnson, J. Chromatogr. A, 1026, 295 (2004).

18. C. Basheer, A. Jayaraman, M.K. Kee, S. Valiyaveettil and H.K. Lee, J. Chromatogr. A, 1100, 137 (2005).

19. M. Kawaguchi, Y. Ishii, N. Sakui, N. Okanouchi, R. Ito, K. Inoue, K. Saito and H. Nakazawa, J. Chromatogr. A, 1049, 1 (2004). 